\title{
COMPUTATIONAL AEROHEATING PREDICTIONS FOR MARS LANDER CONFIGURATIONS
}

\author{
Karl T. Edquist* and Stephen J. Alter ${ }^{\dagger}$ \\ NASA Langley Research Center \\ Hampton, Virginia
}

\begin{abstract}
The proposed Mars Science Laboratory (MSL) mission is intended to deliver a large rover to the Martian surface within $10 \mathrm{~km}$ of the target site. This paper presents computational fluid dynamics (CFD) predictions of forebody heating rates for two MSL entry configurations with fixed aerodynamic trim tabs. Results are compared to heating on a 70-deg sphere-cone reference geometry. All three heatshield geometries are designed to trim hypersonically at a $16 \mathrm{deg}$ angle of attack in order to generate the lift-to-drag ratio (L/D) required for precision landing. Comparisons between CFD and tunnel data are generally in good agreement for each configuration, but the computations predict more flow separation and higher heating on a trim tab inclined 10 deg relative to the surface. CFD solutions at flight conditions were obtained using an 8-species Mars gas in chemical and thermal nonequilibrium. Laminar and Baldwin-Lomax solutions were used to estimate the effects of the trim tabs and turbulence on heating. A tab extending smoothly from the heatshield flank is not predicted to increase laminar or turbulent heating rates above the reference levels. Laminar heating on a tab deflected 10 deg from the conical heatshield is influenced by flow separation and is up to $35 \%$ above the baseline heating rate. The turbulent solution on the inclined tab configuration predicts attached flow and a $43 \%$ heating increase above the reference level.
\end{abstract}

NOMENCLATURE

$\begin{array}{ll}A & \text { axial force }(N) \\ C_{D} & \text { drag coefficient, } D / \rho_{\infty} V_{\infty}{ }^{2} S_{r e f} \\ C G & \text { center of gravity } \\ D & \text { heatshield diameter }(m) \text { or drag }(N) \\ D_{t a b} & \text { heatshield diameter with a tab }(m) \\ h & \text { altitude }(\mathrm{km}) \\ L & \text { lift }(N) \\ L / D & \text { lift-to-drag ratio } \\ M & \text { Mach number } \\ M S L & \text { Mars Science Laboratory } \\ m & \text { aeroshell mass }(\mathrm{kg}) \\ N & \text { normal force }(N) \\ p & \text { pressure }\left(N / \mathrm{m}^{2}\right) \\ q & \text { heating rate }\left(W / \mathrm{cm}^{2}\right) \\ R_{n} & \text { nose radius }(m) \\ R_{s} & \text { shoulder radius }(m) \\ R e & \text { Reynolds number } \\ S & \text { heatshield surface area }\left(\mathrm{m}^{2}\right) \\ S_{r e f} & \text { reference area, } \pi D^{2} / 4\left(\mathrm{~m}^{2}\right) \\ T & \text { temperature }(K) \\ T P S & \text { Thermal Protection System }\end{array}$

\footnotetext{
* Vehicle Analysis Branch, Senior Member, AIAA.

${ }^{\dagger}$ Aetothermodynamics Branch, Senior Member, AIAA.

Copyright $\bigcirc 2003$ by the American Institute of Aeronautics and Astronautics, Inc. No copyright is asserted in the United States under Title 17, U.S. Code. The U.S. Government has a royalty-free license to exercise all rights under the copyright claimed herein for Governmental Purposes. All other rights are reserved by the copyright owner.
}

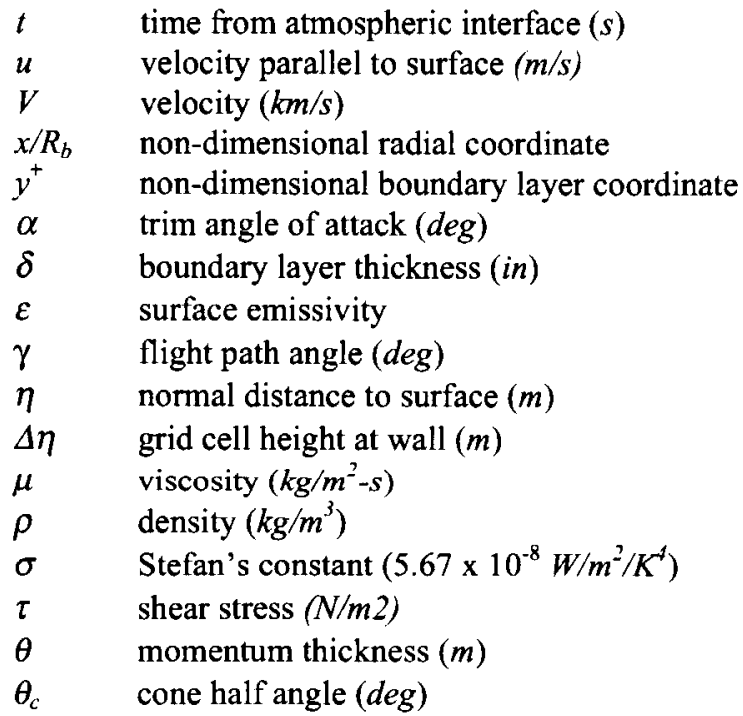

\begin{tabular}{ll}
\multicolumn{2}{l}{ Subscripts } \\
$D$ & heatshield diameter \\
$e$ & boundary layer edge \\
$F R$ & Fay-Riddell formula \\
lam & laminar \\
turb & turbulent \\
$w$ & wall \\
$\theta$ & momentum thickness \\
$\infty$ & freestream
\end{tabular}




\section{INTRODUCTION}

The Viking and Pathfinder missions successfully used ballistic entry trajectories to land on Mars with a target accuracy on the order of $100 \mathrm{~km}$. Second generation missions, such as the proposed Mars Science Laboratory (MSL), will be designed to land with small footprints $(<10 \mathrm{~km})$ at areas that are of particular scientific interest ${ }^{1,2}$. The capability for precision landing, terrain hazard detection and avoidance, and soft touchdown proposed for MSL will allow targeting and exploration of sites that are otherwise unreachable.

Guided atmospheric entry is proposed for MSL to achieve $10 \mathrm{~km}$ landing accuracy. Figure 1 depicts a sample entry, descent, and landing sequence using a two-parachute decelerator system. The guidance algorithm controls trajectory cross range and down range using vehicle lift in order to reach the desired supersonic parachute deployment conditions. Entry vehicle lift mitigates uncertainties in predicted entry states, atmospheric properties, aerodynamics, etc. that otherwise would result in a much larger landing footprint. A hypersonic lift-to-drag ratio $(L / D)$ of 0.22 0.25 (trim angle of attack $a=16 \mathrm{deg}$ ) and ballistic coefficient $\left(\mathrm{m} / C_{D} S_{r e f}\right)$ less than $120 \mathrm{~kg} / \mathrm{m}^{2}$ satisfy the delivery requirements for a 2005 launch.

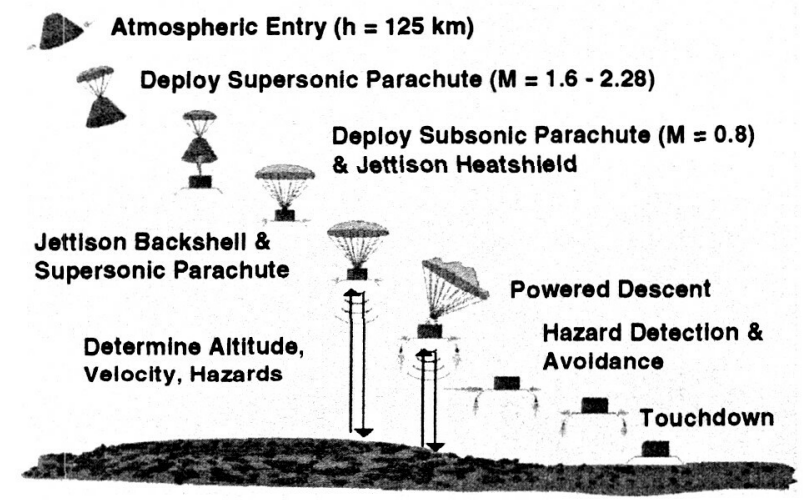

Figure 1. Sample MSL Entry, Descent, and Landing Sequence

The baseline MSL aeroshell has a 4.05-m diameter, 70-deg sphere-cone heatshield that draws from Viking and Pathfinder heritage. Figure 2 shows a sample spacecraft cruise configuration with the aeroshell and cruise stage attached through the heatshield. The aeroshell will separate from the cruise stage prior to atmospheric interface and decelerate the spacecraft to supersonic speeds before parachute deployment. During the hypersonic portion of entry, the aeroshell must protect the spacecraft components from significant aerothermal loads.

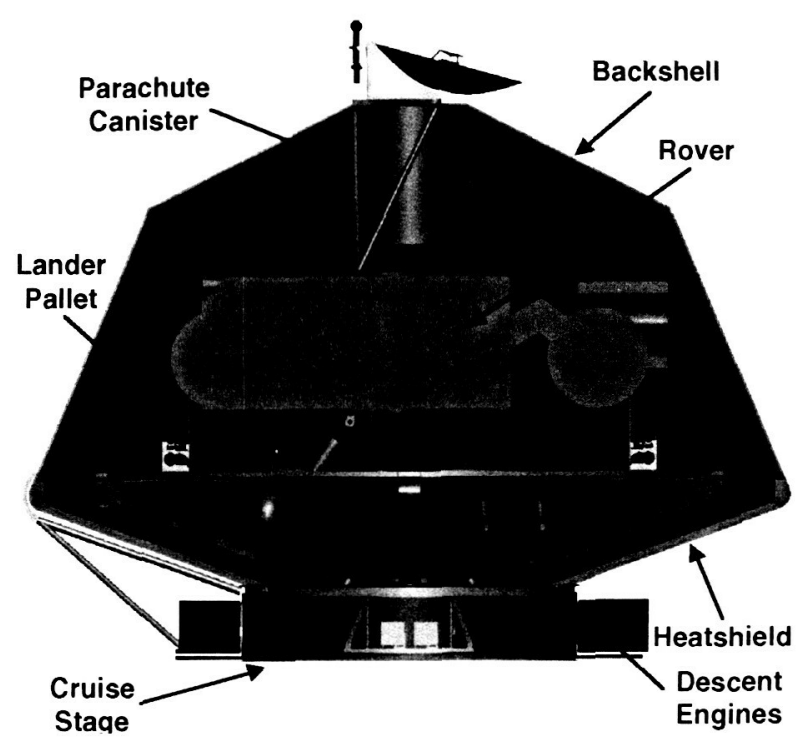

Figure 2. Sample MSL Cruise Configuration

Blunt body lift is generated from axial force and is in the direction opposite the trim angle (Fig. 3). Trim conditions can be achieved with either radial center of gravity (CG) offset or an aerodynamic trim tab, or a combination of both. Using a fixed control flap may reduce the amount of ballast mass and relax internal packaging requirements needed to shift the radial CG.

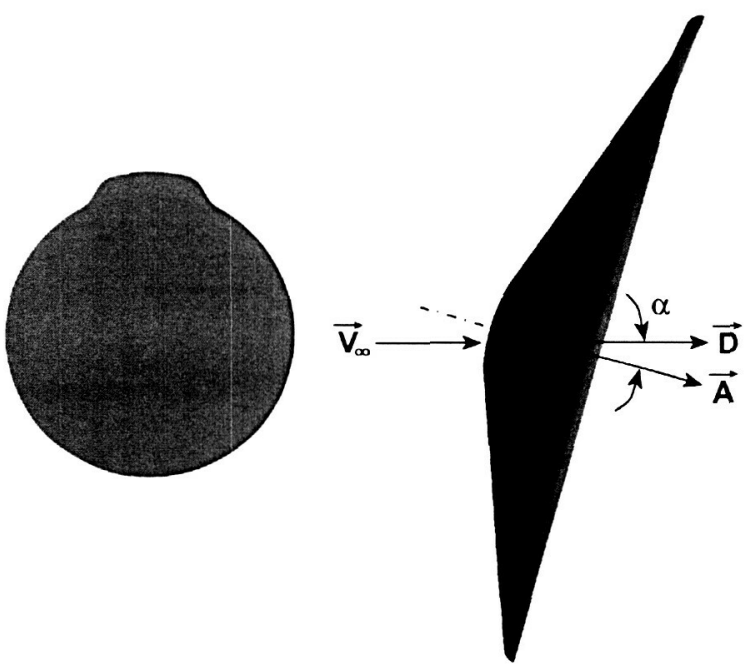

Figure 3. Blunt Body Trim Using a Fixed Tab

If a trim tab is used instead of $\mathrm{CG}$ offset alone to achieve the required $L / D$, the flap heating environments are of particular interest. A trim tab would be exposed to high heating during entry, possesses a low thermal mass that can result in significant integrated heating, has a complex curved surface that presents manufacturing challenges, and may require adjoining dissimilar TPS materials that can recede unevenly. 


\section{Heatshield Configurations}

Aeroheating predictions are presented for three heatshield geometries: the reference axisymmetric shape and two configurations with fixed trim tabs (Fig. 4). The flap on the Shelf configuration is a smooth extension of the forebody, whereas the Canted tab is inclined $10 \mathrm{deg}$ relative to the flank. The Shelf and Canted geometries have $4.3 \%$ and $2.7 \%$ more surface area, respectively, than the Baseline shape. Both tabs were sized to eliminate the need for a CG offset. Table 1 summarizes the geometric dimensions.

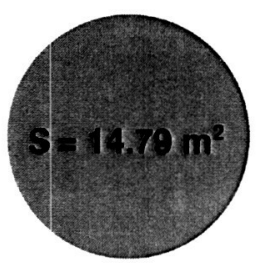

Baseline

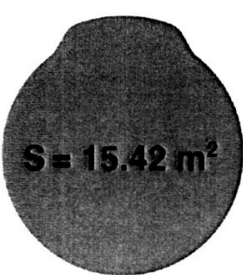

Shelf

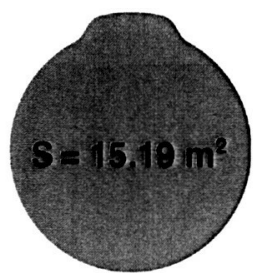

Canted
$\mathbf{R}_{\text {s }}$

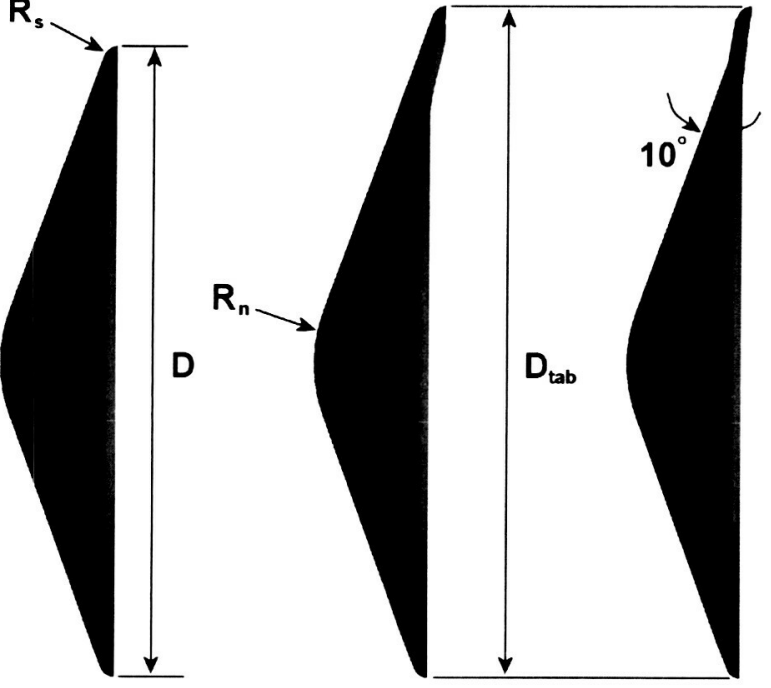

Figure 4. Heatshield Configurations: Front (Top) and Side (Bottom) Views

Table 1. Heatshield Dimensions

\begin{tabular}{|c|c|}
\hline Parameter & Value \\
\hline$\theta_{c}$ & 70 \\
\hline$D$ & 4.05 \\
\hline$D_{t a b}$ & 4.31 \\
\hline$R_{n}$ & 0.9854 \\
\hline$R_{s}$ & 0.0988 \\
\hline
\end{tabular}

This paper compares predicted aeroheating for the candidate heatshield geometries. Reference 3 contains a detailed discussion of the Baseline aeroheating environments at multiple trajectory conditions. Select results are repeated here and compared to the Shelf and Canted heating. References 4-9 present various analyses of the candidate MSL shapes: experimental aeroheating ${ }^{4-6}$, supersonic aerodynamics ${ }^{7,8}$, and entry trajectory simulations ${ }^{9}$. CFD results in the present study are compared to data from Reference 6 for all three configurations.

\section{Atmospheric Entry Trajectory}

The MSL aeroheating analysis requires knowledge of the atmospheric entry path. The nominal, or expected, entry trajectory for the 2005 launch opportunity was calculated using the Program to Optimize $\underline{\text { Simulated }}$ Trajectories $(\mathrm{POST})^{10}$. Figure 5 shows the corresponding velocity-altitude map. Stagnation point heating rate, dynamic pressure, and Reynolds number are plotted versus time in Figure 6. The heating rate estimate is based on the Fay-Riddell ${ }^{11}$ formula for a sphere at $\alpha=0$. CFD solutions were obtained for the peak stagnation point heating time at the freestream conditions summarized in Table 2.

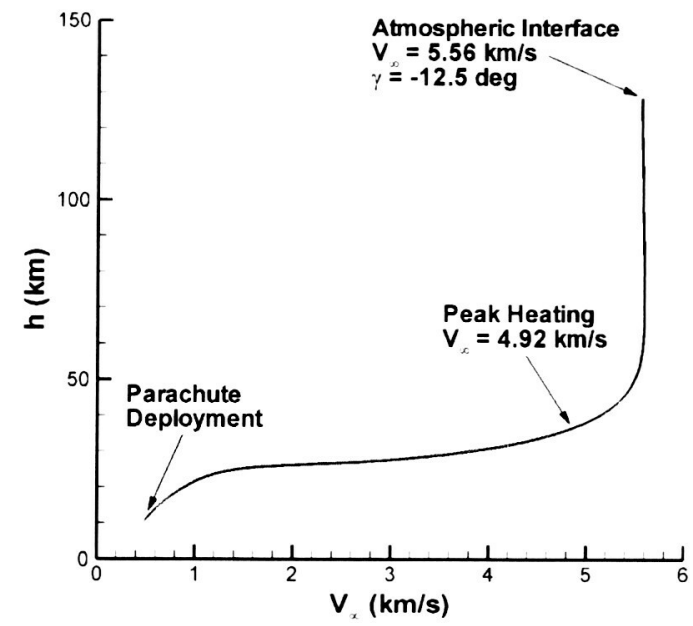

Figure 5. Nominal Entry Trajectory for the $\mathbf{2 0 0 5}$ Launch Opportunity

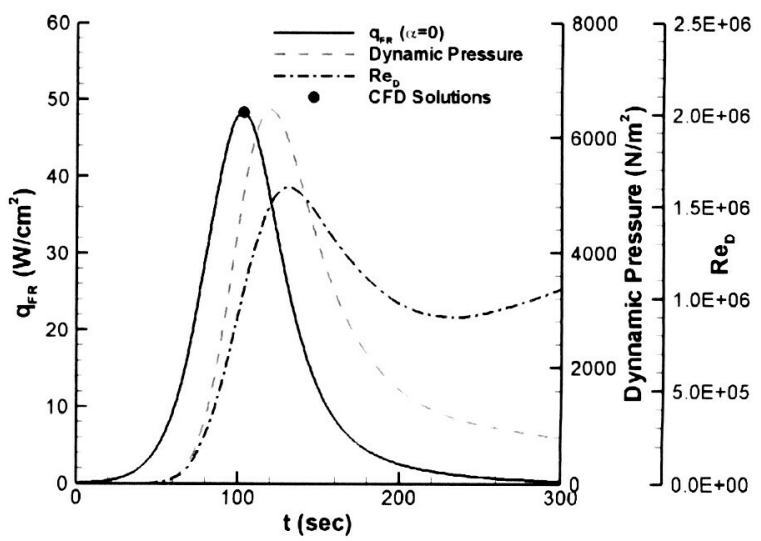

Figure 6. Stagnation Point Heating Rate, Dynamic Pressure, and Reynolds Number 
Table 2. Peak Heating Point Freestream Conditions

\begin{tabular}{|c|c|}
\hline$t(\mathrm{sec})$ & 103 \\
\hline$h(\mathrm{~km})$ & 37.1 \\
\hline$V_{\infty}(\mathrm{m} / \mathrm{s})$ & 4919 \\
\hline$\rho_{\infty}\left(\mathrm{kg} / \mathrm{m}^{3}\right)$ & $4.15 \times 10^{-4}$ \\
\hline$T_{\infty}(\mathrm{K})$ & 159.3 \\
\hline$M_{\infty}$ & 24.7 \\
\hline$R e_{D}$ & $1.04 \times 10^{6}$ \\
\hline
\end{tabular}

ANALYSIS

\section{Computational Approach}

CFD modeling will be combined with an experimental test program to predict the MSL flight vehicle aerothermal environments. Hypersonic flight conditions in a reacting Mars atmosphere gas cannot be recreated in an experimental environment, so the use of numerical tools is a critical part of the MSL aeroheating analysis. The continued improvement of grid generation methods, flow solvers, and computational resources makes it possible to solve three-dimensional, chemically-reacting flowfields that once were prohibitive.

\section{LAURA CFD Code}

Aeroheating calculations were performed using the Langley Aerothermodynamic Upwind Relaxation Algorithm (LAURA) ${ }^{12}$ CFD code. LAURA has been used previously to predict the aeroheating environments for other Mars applications ${ }^{13,14}$. LAURA models an 8species Mars gas $\left(\mathrm{CO}_{2}, \mathrm{CO}, \mathrm{N}_{2}, \mathrm{O}_{2}, \mathrm{NO}, \mathrm{C}, \mathrm{N}, \mathrm{O}\right)$ in chemical and thermal non-equilibrium using the Park$94^{15}$ reaction rates. A finite-volume approach is used to solve the inviscid, thin-layer Navier-Stokes (TLNS), or full Navier-Stokes flowfield equations. The TLNS option was used for all calculations presented here. The code uses Roe's averaging ${ }^{16}$ for the inviscid fluxes with second-order corrections using Yee's symmetric total variation diminishing (TVD) scheme ${ }^{17}$.

A super-catalytic wall boundary condition was used in which the species mass fractions for $\mathrm{CO}_{2}$ and $\mathrm{N}_{2}$ are fixed at their freestream values of 0.97 and 0.03 , respectively. A radiative-equilibrium temperature was imposed at the wall to satisfy the following relation:

$$
q_{w}=\varepsilon \sigma T_{w}^{4}
$$

A fixed surface emissivity $(\varepsilon)$ of 0.9 was used for all solutions. The wall is assumed to radiate to a temperature of absolute zero.

\section{Turbulence Modeling}

Turbulent LAURA solutions were obtained with the Baldwin-Lomax algebraic model ${ }^{18.19}$. The model is believed to give reasonable heating estimates for simple shapes, such as a sphere-cone. A transition location is required input and was specified to give conservative fully turbulent results. The Dhawan-Narashima bridging model ${ }^{20}$ is employed in LAURA to blend the laminar and turbulent regions of the flowfield, but it is not intended to predict transition onset. More refined turbulence modeling (i. e. two-equation models) is recommended as the MSL aeroshell design matures, especially if a trim tab is used.

\section{Grid Adaptation}

LAURA is capable of grid alignment in which the computational mesh can be adapted to the boundary layer and bow shock based on user-defined parameters. Proper mesh resolution at the wall is necessary for reliable heating predictions. In LAURA, a userspecified cell Reynolds number controls the grid spacing at the wall:

$$
R e_{\varkappa^{\prime}}=\left(\frac{\rho a \Delta \eta}{\mu}\right)_{w}
$$

Experience has shown that reliable laminar heating predictions can be achieved with $R e_{w}=10$. Wall cell size for turbulent calculations was specified to insure sufficient resolution of the viscous sub-layer. A $R e_{w}$ value of 2 was used and generally resulted in $y^{+}$of order 0.1 :

$$
y^{+}=\frac{\eta \rho}{\mu} \sqrt{\frac{\tau_{\omega}}{\rho}}
$$

\section{Computational Grids}

Singularity-free, structured volume grids were used for LAURA solutions on the Baseline, Shelf, and Canted configurations. Figure 7 shows surface and symmetry plane grids coarsened by a factor of two in each direction. Only half of the heatshield is modeled due to symmetry in the pitch plane. A 7-block mesh was used for the Baseline shape and 11-block grid systems were used for the Shelf and Canted copfigurations. The heatshield nose on each shape was meshed to avoid a singularity pole boundary that can introduce artificial discontinuities into the flowfield. 


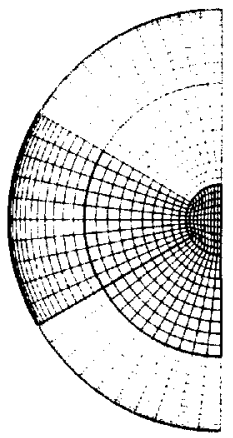

Baseline

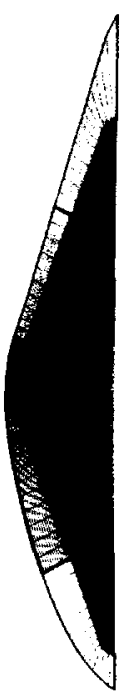

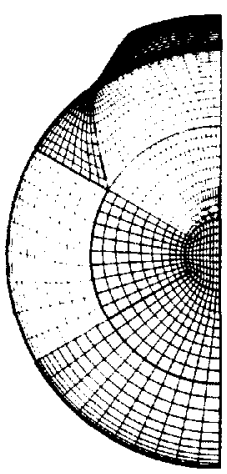

$$
\text { Shelf }
$$

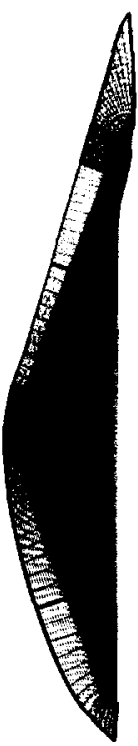

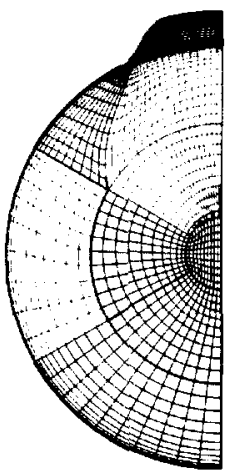

Canted

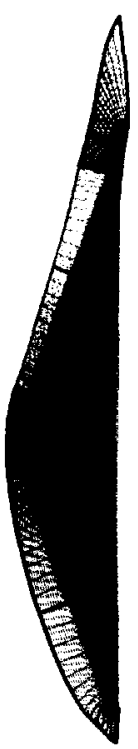

Figure 7. Surface (Top) and Symmetry Plane (Bottom) Grids Used for CFD Solutions (Coarsened)

The grids were built using GridGen ${ }^{21}$ to construct the topology and surface distribution, 3DGRAPE/AL ${ }^{22}$ to generate the volume grid, and the Volume Grid Manipulator (VGM) ${ }^{23}$ to enhance grid quality and impose boundary conditions along block interfaces. The Baseline surface grid has 3280 cells, and the Shelf and Canted surface grids each have 8048 cells. The nominal meshes contain 64 cells in the surface normal direction. The grid distributions around the Shelf and Canted flaps were designed to accurately represent the surface geometry and sufficiently capture flowfield features caused by the tabs.

\section{RESULTS AND DISCUSSION}

LAURA perfect gas predictions are compared to select experimental data for the candidate MSL configurations. Laminar and turbulent predictions at flight conditions are shown for the peak heating time on the nominal trajectory. Select Baseline results are repeated from Reference 3 and compared with Shelf and Canted predictions to estimate trim tab effects.

\section{CFD vs. Tunnel Data}

Reference 6 reported experimental results from NASA LaRC's 20-Inch Mach 6 Air Tunnel. Global heating data were obtained on the candidate geometries using the two-color, relative-intensity, phosphor thermography method. See Reference 6 for a detailed description of the facility, data acquisition, and test conditions. Figure 8 compares normalized heating data on the top half of the geometries at $a=20 \mathrm{deg}$ and $R e_{\infty}$ $=3.0 \times 10^{6} / \mathrm{ft}$. The Baseline and Shelf heating rates are essentially the same. Heating on the Canted model decreases ahead of the tab before increasing at the tab hinge line. It was inferred from this heating profile that the Canted tab caused flow separation.

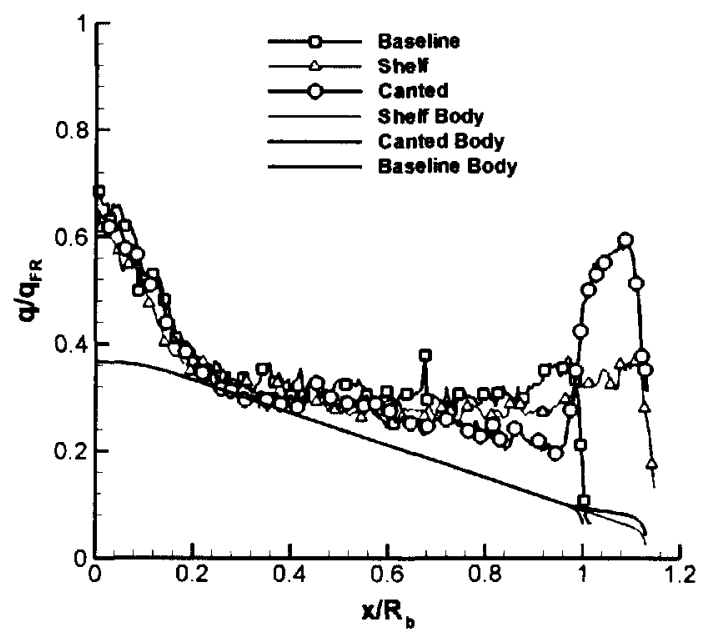

Figure 8. Comparison of Heating Rate Data at $a=$ $20 \mathrm{deg}$ and $R e_{\infty}=3.0 \times 10^{6} / f t$ (from Ref. 6)

LAURA solutions were run with perfect gas air and a constant wall temperature of $300 \mathrm{~K}$. Comparisons between the computations and data from Figure 8 are shown in Figure 9. The estimated experimental uncertainty is $+1-13 \%$ and is shown with the data. LAURA predictions are generally within the Baseline and Shelf data uncertainty. Predicted heating spikes at the shoulder do not show up in the data possibly because of model conduction effects. Computed heating on the Canted geometry agrees well with data on the conical flank, but tab heating is above the upper data boundary. The LAURA heating profile indicates a larger flow separation region ahead of the flap and stronger reattachment, which may explain the higher predicted tab heating levels. Further comparisons between CFD and tunnel data will be performed as the MSL aeroshell design matures. 

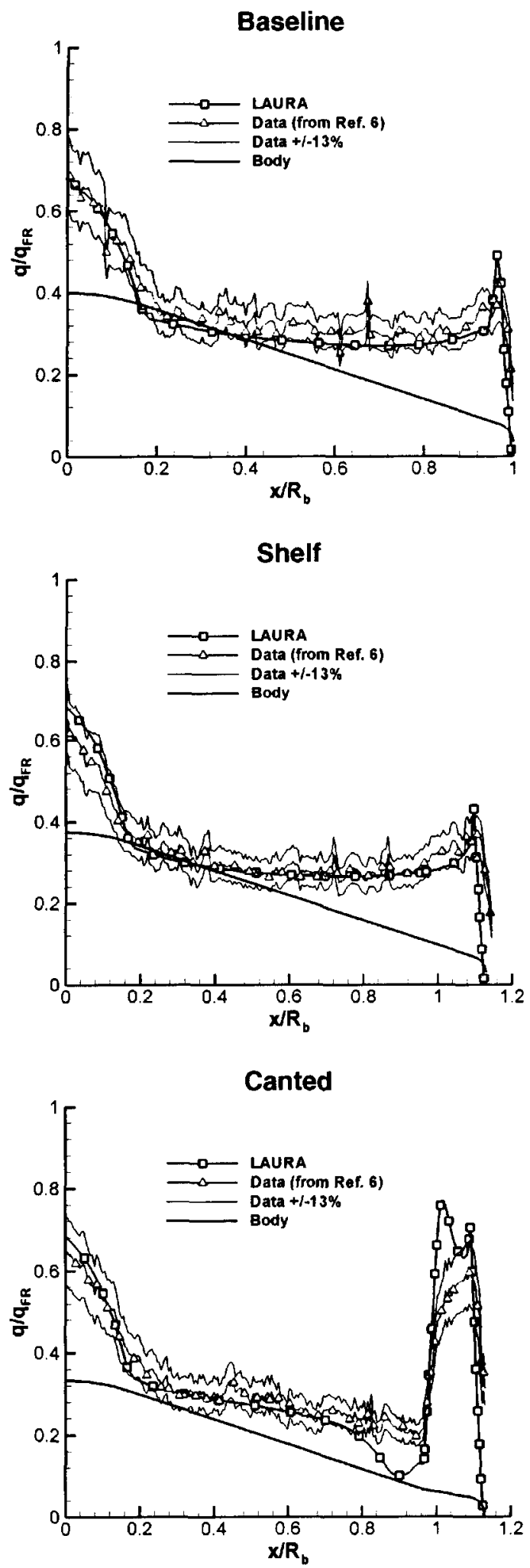

Figure 9. Comparisons of LAURA and Heating Rate Data at $a=20 \mathrm{deg}$ and $R e_{\infty}=3.0 \times 10^{6} / \mathrm{ft}$ (Data from Ref. 6)

\section{Laminar CFD Flight Predictions}

Computations at flight conditions were used to estimate the trim tab effects on the Shelf and Canted heating environments. Figure 10 compares LAURA laminar symmetry plane heating rates at the nominal trajectory peak heating time and $\alpha=16 \mathrm{deg}$. The conical flank heating is generally higher on the windward side where the stagnation point is located. The nose experiences higher heating than the stagnation point even though they do not coincide. As expected, heating rates on the windward side are identical for all three geometries. Rapid flow expansion around the heatshield shoulder causes a spike in heating that can be mitigated by increasing the radius of curvature.

The Shelf flap does not increase heating above the Baseline level. This is reasonable since the Shelf flap is an extension of the heatshield flank that does not introduce flow separation. The heating rate continues to decrease along the extra running length provided by the Shelf tab. Heating ahead of the Canted flap follows the Baseline level before passing through a pronounced drop and sharp rise along the flap corresponding to the starting and ending points of a separated flow region. The predicted heating rate on the Canted flap is as high as $49 \mathrm{~W} / \mathrm{cm}^{2}$, which is approximately $35 \%$ higher than the laminar heating rate at the nose.

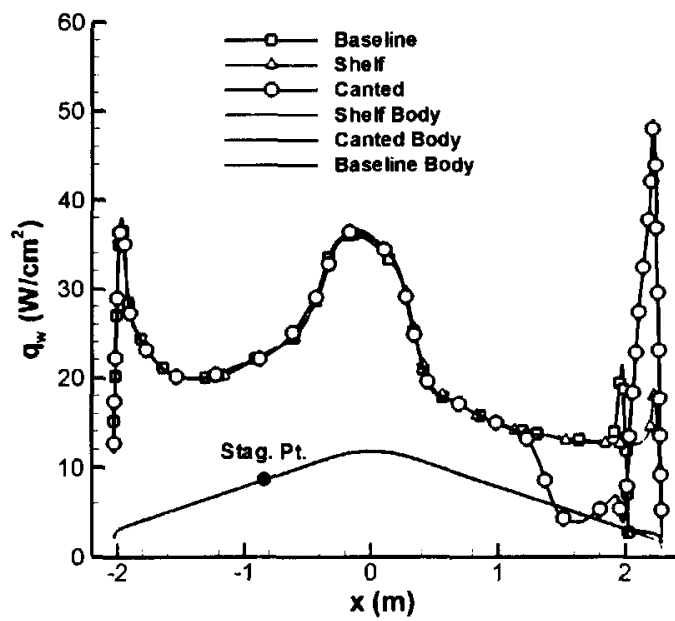

Figure 10. Laminar Symmetry Plane Heating Rate Comparison $(a=16 \mathrm{deg})$

Figure 11 illustrates the beginning of flow separation ahead of the Canted flap and reattachment near the tab edge. The detached flow region spans the width of the flap and wraps around the tab sides as the flow expands. The recirculating flow pocket is centered at the tab hinge line and is followed by a weak shock at the reattachment point. 


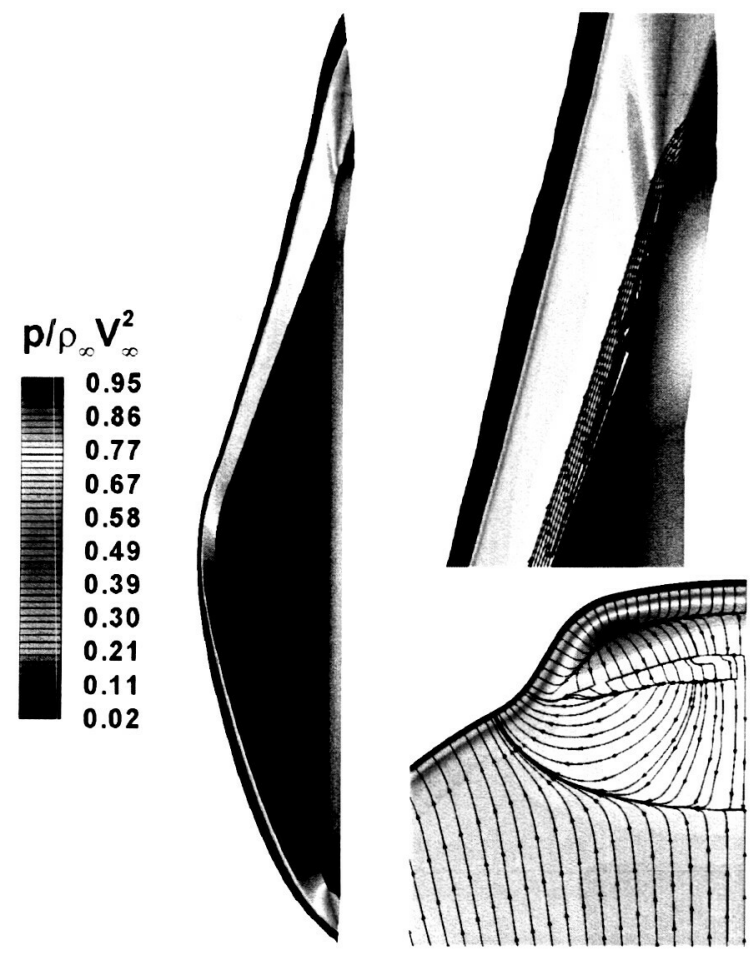

Figure 11. Laminar Pressure and Streamlines for the Canted Configuration $(a=16 \mathrm{deg})$

A plot of surface pressure, streamlines, and heating rate on the Canted geometry is shown in Figure 12. The separated flow ahead of the flap is easily identified in the heating rate distribution. Reduced heating in front of the tab corresponds with the separated flow region. Peak heating occurs after reattachment as the flow accelerates around the tab edge. Heating rate on the corner is about $55 \mathrm{~W} / \mathrm{cm}^{2}$, or $12 \%$ higher than the symmetry plane value; a larger radius of curvature would reduce the heating.

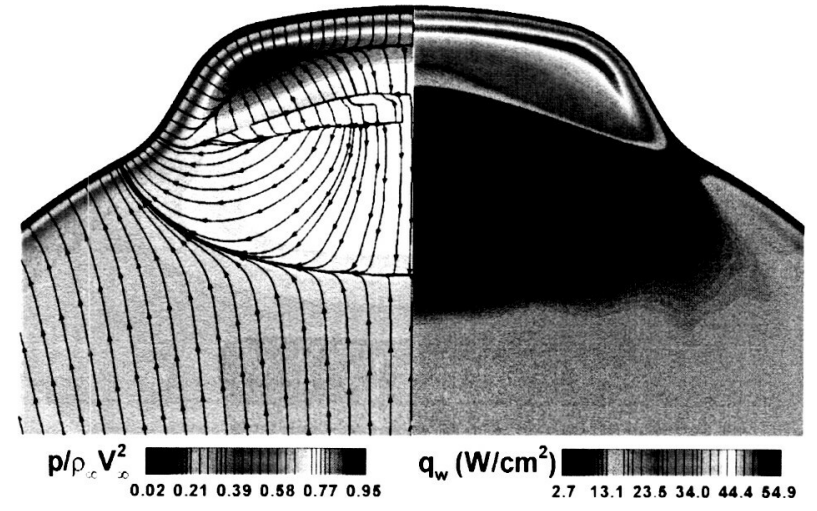

Figure 12. Laminar Pressure and Streamlines (Left) and Heating Rate (Right) on the Canted Configuration $(a=16 \mathrm{deg})$
If the tab experiences elevated heating throughout the trajectory, the integrated heat load will be of concern because the TPS and structure in that area must perform at high temperatures. The heating problem is compounded by the fact that the exposed tab has low thermal mass and limited conduction paths through which heat is carried away from the flap area. Consequently, thermal soak may cause tab temperatures to continue rising after the applied heat pulse has ended.

Figure 13 compares symmetry plane pressure between the configurations. The pressure is highest on the windward conical flank where the stagnation point is located, and is somewhat lower on the opposite side. The detached flow ahead of the Canted tab causes an increase in pressure, followed by another pressure jump near the flap hinge line. Pressure on the Canted tab is lower than the stagnation level. The higher pressure on the Canted flap allows it to generate the desired trim angle of attack with less surface area than the Shelf geometry.

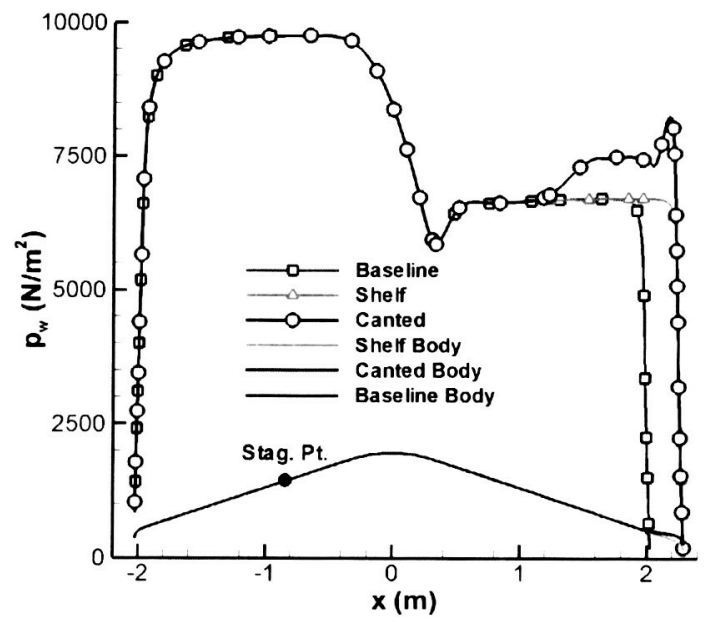

Figure 13. Laminar Symmetry Plane Pressure Comparison $(a=16 \mathrm{deg})$

\section{Canted Grid Refinement Study}

LAURA heating predictions were run until a grid-converged solution was obtained $i$. e. the heating is essentially unchanged with additional grid adaptations. A grid-independent solution is also desired, which means that the heating predictions do not change significantly for a more refined surface and/or volume grid. It was shown in Reference 3 that 64 normal cells are sufficient for grid-independent Baseline heating solutions. The same is also believed to be true for the Shelf heatshield because the trim flap is a smooth extension of the conical flank and does not cause flow separation. Thus, heating solutions on Baseline and Shelf are shown only for grids with 64 normal cells. 
The Canted shape is unique because the trim tab induces flow separation whose recirculation pockets can be difficult to solve in a steady state solution. Consequently, the Canted was the most challenging of the three geometries for obtaining grid-converged and grid-independent laminar heating. In fact, global timestepping was used at times to advance the flowfield solutions and allow the recirculating flow to stabilize.

A grid refinement study was conducted to determine whether the reference Canted mesh with 64 normal cells was sufficient to obtain reliable laminar heating predictions. The original surface grid was used and the number of surface normal cells was increased to 96. Values of $R e_{w}=10$ and $R e_{w}=1$ were used to determine the effects of additional grid cells in the boundary layer and finer grid spacing at the wall.

Figure 14 compares laminar heating predictions on Canted grids with $64\left(R e_{w}=10\right)$ and $96\left(R e_{w}=10\right.$ and $\left.R e_{w}=1\right)$ surface normal cells. Figure 15 shows an enlarged view of the flap region. The heating rate on the conical flank is unaffected by the number of grid cells or wall spacing. All three solutions exhibit flow detachment before the tab hinge line and a heating spike near the edge. Minor heating differences exist between the grids in the detached flow region and along the tab face. Table 3 summarizes the peak heating rates along the symmetry plane. The range of heating rates on the tab edge is $45.6-48.6 \mathrm{~W} / \mathrm{cm}^{2}$, for a variation of less than $+/-3.5 \%$ from the mean value. This range of heating rates is considered to be within the CFD model uncertainties and small enough to satisfy grid independent heating with respect to surface normal grid spacing. Ideally, solutions on a finer surface mesh also should be performed, but time and resource constraints prevented such an analysis in the present study.

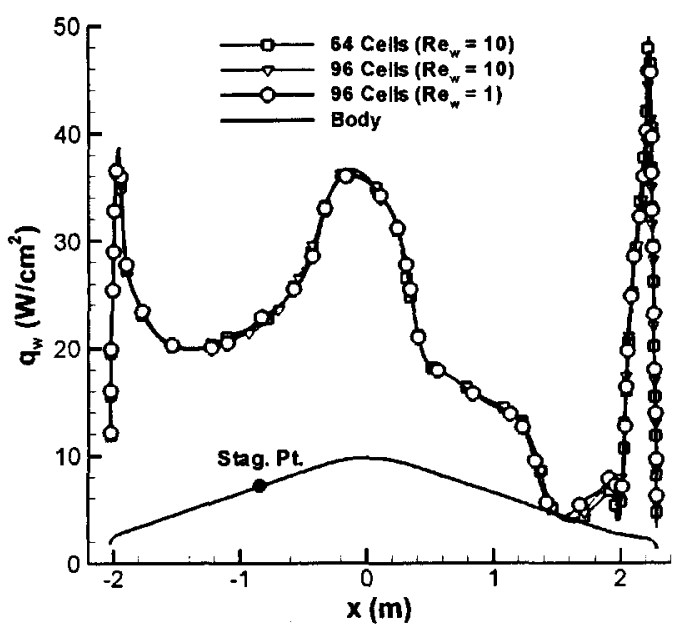

Figure 14. Laminar Grid Refinement Study on the Canted Configuration

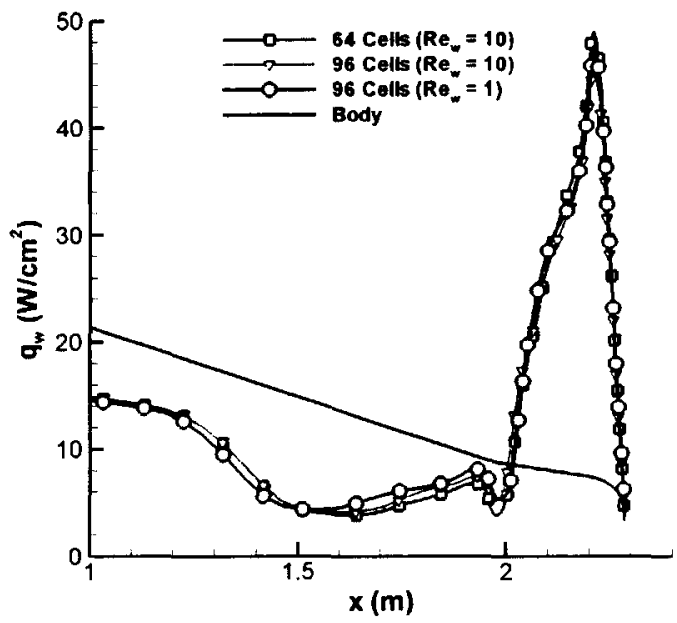

Figure 15. Laminar Grid Refinement Study on the Canted Configuration (Enlarged View)

Table 3. Peak Laminar Symmetry Plane Heating Rates on Canted Configuration Grids

\begin{tabular}{|c|c|c|}
\hline $\begin{array}{c}\text { No. of Surface } \\
\text { Normal Cells }\end{array}$ & $R e_{w}$ & Peak $q_{w}\left(\mathrm{~W} / \mathrm{cm}^{2}\right)$ \\
\hline 64 & 10 & 48.6 \\
\hline 96 & 10 & 45.6 \\
\hline 96 & 1 & 47.6 \\
\hline
\end{tabular}

\section{Turbulent CFD Flight Predictions}

Reference 3 showed that turbulent transition is likely to occur before the peak heating point on the nominal trajectory. Natural transition using a momentum-thickness Reynolds number criteria of $R e_{\theta}$ $>200$ and transition due to heatshield penetrations were both predicted to result in a turbulent boundary layer. $R e_{\theta}$ is commonly used as an indicator of smooth body transition and is based on the boundary layer edge properties and momentum thickness $(\theta)$ :

$$
\begin{gathered}
\operatorname{Re}_{\theta}=\frac{\rho_{e} u_{e} \theta}{\mu_{e}} \\
\theta=j_{0}^{\infty} \frac{\rho u}{\rho_{e} u_{e}}\left(1-\frac{u}{u_{e}}\right) d \eta
\end{gathered}
$$

The boundary layer edge is defined as the location where total enthalpy is $99.5 \%$ of the freestream value.

If turbulence does occur before the time of peak heating, it will significantly augment the heating rates and integrated heat load. An estimate of the turbulence effects was accomplished using Baldwin-Lomax 
computations on all three configurations. Reference 3 reported more than a $70 \%$ turbulent increase in heating above the laminar nose level on the Baseline geometry. Those results are repeated here and compared to Shelf and Canted predictions.

Turbulent heating rate along the symmetry plane of each configuration is shown in Figure 16. Contrary to the laminar profiles, the turbulent heating is higher on the leeward flank where boundary layer running length is largest. Again, the Baseline and Shelf heating rates are similar and peak at about $63 \mathrm{~W} / \mathrm{cm}^{2}$. The longer running length on the Shelf heatshield does not result in additional turbulent heating augmentation. Turbulent heating on the Canted shape is identical to the Baseline levels on the commonly shared geometry. At the Canted tab hinge line, the heating immediately increases due to the surface inclination change. The heating rate across the entire tab face is elevated above the Baseline turbulent level. The heating rate on the Canted flap is $83-90 \mathrm{~W} / \mathrm{cm}^{2}$, or $32-43 \%$ above the Baseline level and $69-84 \%$ higher than the Canted laminar peak value of $49 \mathrm{~W} / \mathrm{cm}^{2}$.

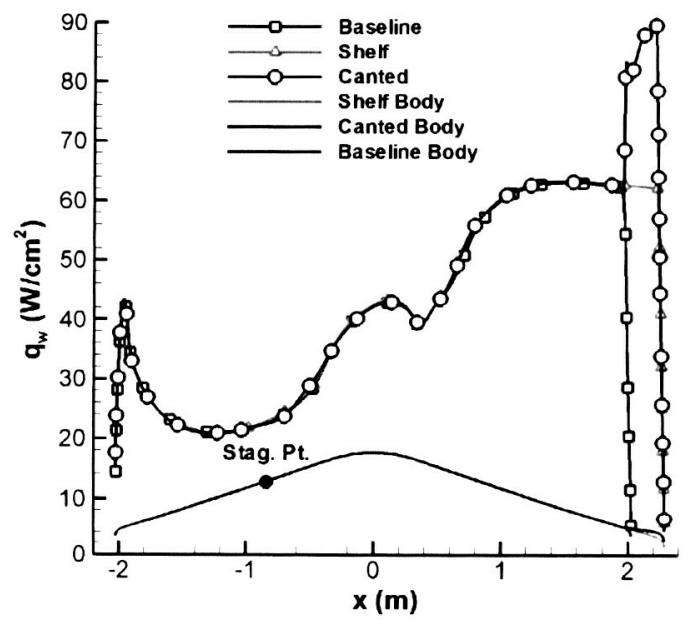

Figure 16. Turbulent Symmetry Plane Heating Rate Comparison $(a=16 \mathrm{deg})$

Elevated heating over the entire Canted flap is the result of attached turbulent flow (Fig. 17). The presence of a fuller and thicker turbulent boundary layer prevents the development of flow separation ahead of the Canted flap, contrary to the laminar case. This is a reasonable result since a turbulent boundary layer has more momentum (compared to a laminar one) with which to overcome a negative pressure gradient. The oblique shock emanating from the flap hinge line is much stronger than the laminar reattachment shock shown previously.

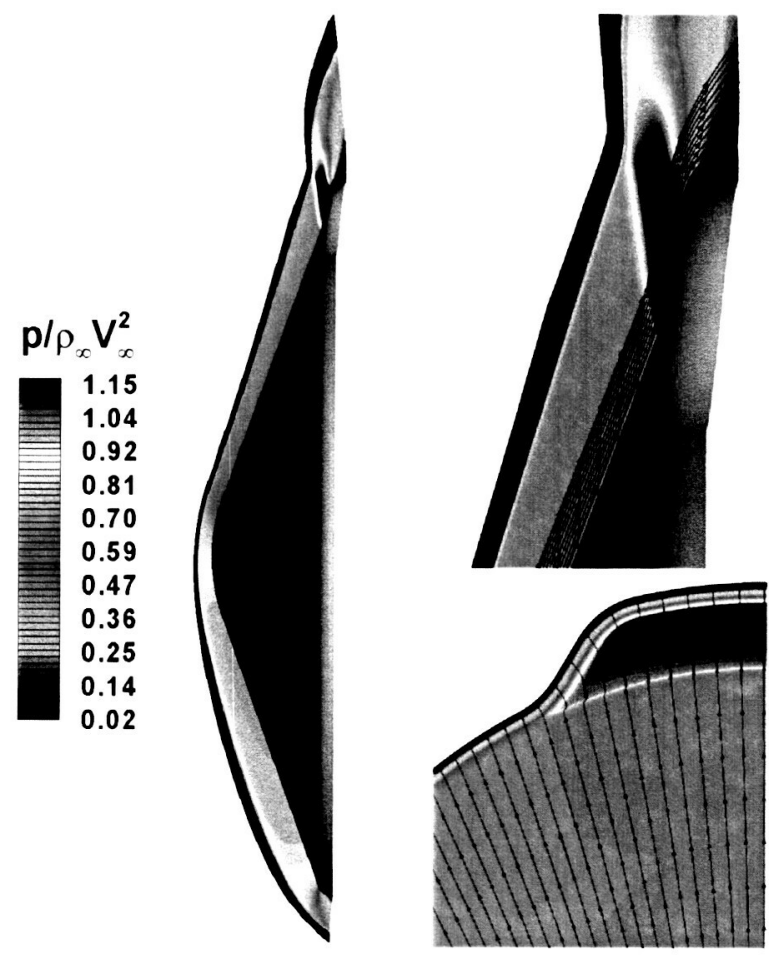

Figure 17. Turbulent Pressure and Streamlines for the Canted Configuration $(a=16 \mathrm{deg})$

Surface pressure, streamlines, and heating rate on the Canted geometry in Figure 18 illustrate how attached turbulent flow corresponds to high heating rates on the tab face. The flap causes an immediate jump in pressure at the hinge line. The same is true of the heating rate distribution. Similar to the laminar case, the heating rate at the tab outer edge $\left(98 \mathrm{~W} / \mathrm{cm}^{2}\right)$ is slightly higher than the symmetry plane value and may be reduced with a larger radius of curvature.

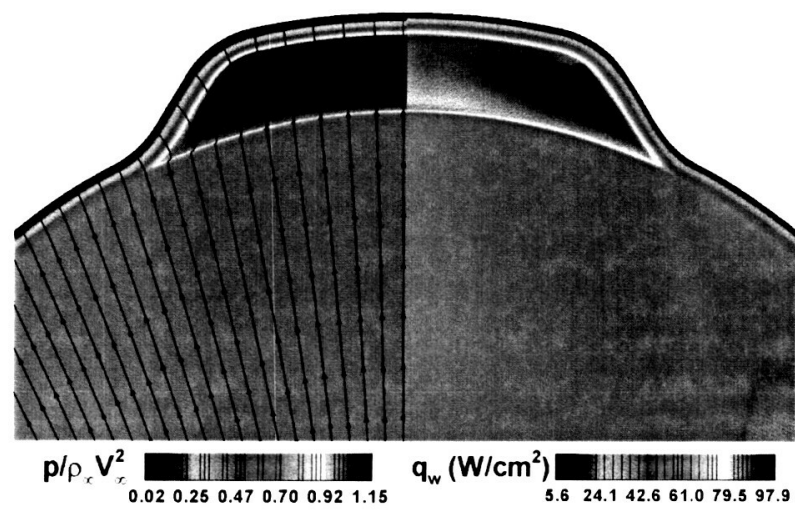

Figure 18. Turbulent Pressure and Streamlines (Left) and Heating Rate (Right) on the Canted Configuration $(a=16 \mathrm{deg})$ 
The turbulent surface pressures for each configuration are shown in Figure 19. Pressure distributions on the Baseline and Shelf geometries are similar to the laminar profiles. The Canted profile shows a much larger pressure jump with attached flow than was predicted for the detached laminar flow case. The pressure along the Canted tab is higher than the stagnation level. If the flow does remain attached on the Canted geometry, higher pressure on the tab would improve its aerodynamic effectiveness.

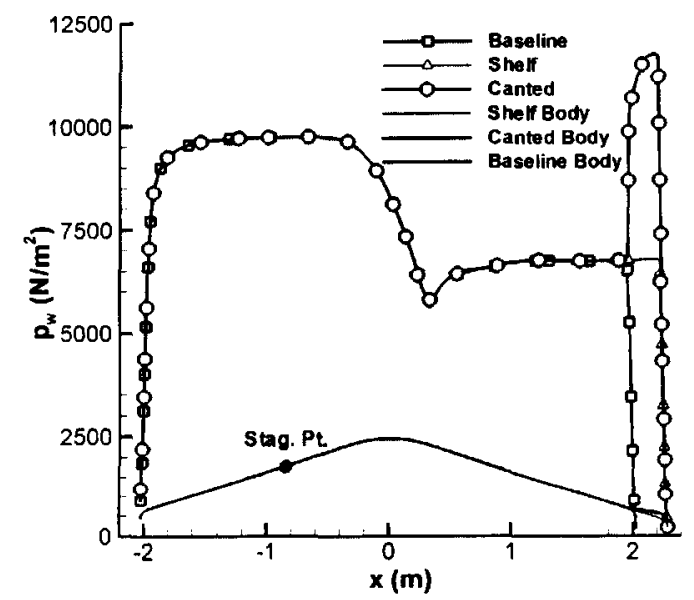

Figure 19. Turbulent Symmetry Plane Pressure Comparison $(a=16 \mathrm{deg})$

Laminar and turbulent heating rates for the Shelf and Canted shapes are repeated in Figure 20. Turbulence is predicted to increase heating over the entire leeward flank for both heatshields. Windward side heating is predicted to increase slightly with turbulent conditions. Table 4 summarizes the peak symmetry plane laminar and turbulent heating rates for all configurations. Turbulent transition augments the Baseline and Shelf heating by the same magnitude of $75 \%$ above the laminar nose level. The increase in peak heating on the Canted configuration is $84 \%$.

There is evidence that worst-case tab heating with flow separation may occur with a laminar incoming boundary layer followed by transitional reattachment $\mathrm{t}^{24}$. It has been suggested that algebraic turbulence models can give reasonable heating estimates by specifying a transition location at reattachment. Furthermore, if the incoming flow is turbulent and is predicted to detach, more advanced turbulence models show promise in predicting heating rates on a deflected flap ${ }^{25}$.
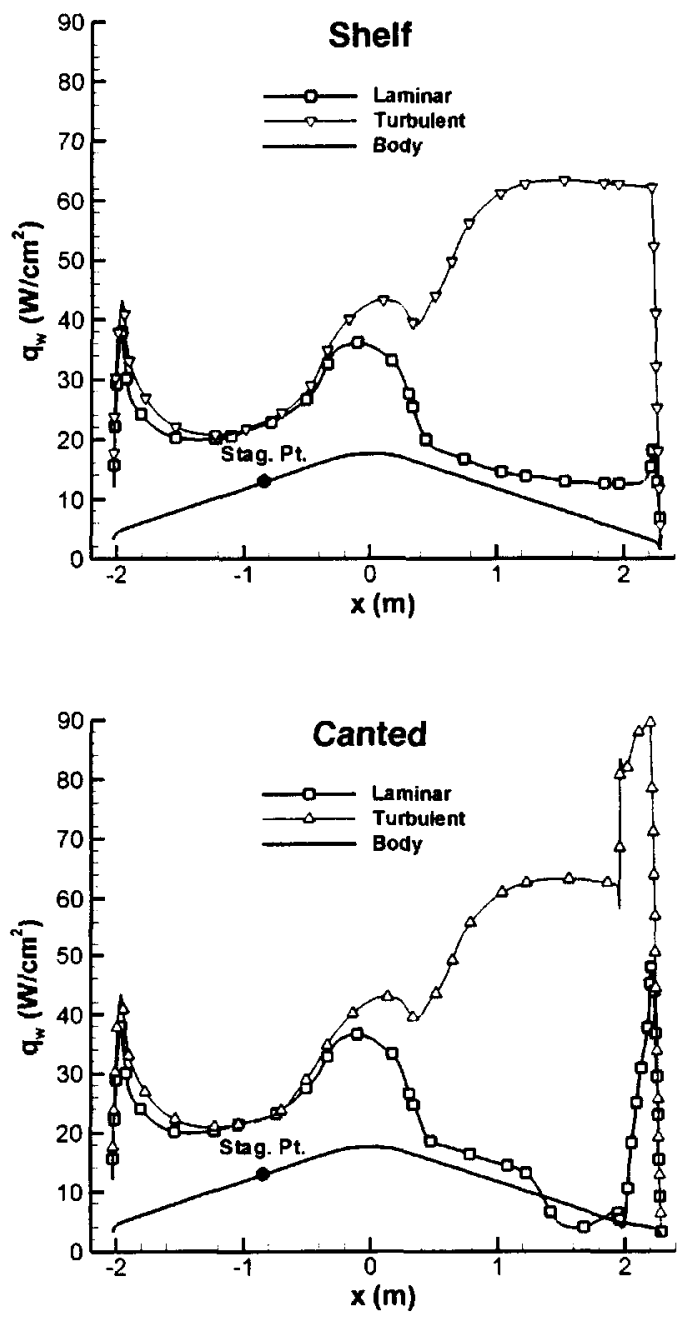

Figure 20. Comparisons of Laminar and Turbulent Heating Rates on the Shelf and Canted Configurations $(a=16 \mathrm{deg})$

Table 4. Peak Laminar and Turbulent Symmetry Plane Heating Rates (* denotes nose value)

\begin{tabular}{|c|c|c|c|}
\hline Configuration & $\begin{array}{c}q_{\text {lam }} \\
\left(\mathrm{W} / \mathrm{cm}^{2}\right)\end{array}$ & $\begin{array}{c}q_{\text {turb }} \\
\left(\mathrm{W} / \mathrm{cm}^{2}\right)\end{array}$ & $q_{\text {lum }} / q_{\text {turb }}$ \\
\hline Baseline & $36^{*}$ & 63 & 1.75 \\
\hline Shelf & $36^{*}$ & 63 & 1.75 \\
\hline Canted & 49 & 90 & 1.84 \\
\hline
\end{tabular}

The current analysis was used to estimate the effects of aerodynamic trim tabs on MSL heating. Numerical modeling of chemically reacting flowfields over deflected control flaps remains a challenging task, especially if flow separation exists. The prediction of attached turbulent flow for a modest control flap angle of $10 \mathrm{deg}$ is plausible given that the turbulent boundary layer has more momentum to overcome a negative pressure gradient. If detached turbulent flow is 
suspected to occur, more advanced techniques are recommended beyond the Baldwin-Lomax model. Additional testing and more refined models will be used to further analyze MSL turbulent heating, especially if a deflected flap is used to trim the entry vehicle.

\section{SUMMARY AND CONCLUSIONS}

Computational aeroheating predictions were obtained for candidate Mars Science Laboratory heatshields designed for a hypersonic lift-to-drag ratio of $0.22-0.25$ at a trim angle of attack of $16 \mathrm{deg}$. The reference Baseline 70-deg sphere-cone geometry achieves trim through an offset radial center of gravity. The Shelf and Canted geometries have fixed tabs that generate trim conditions through asymmetric loading. The Shelf tab extends smoothly from the heatshield flank and the Canted flap is deflected $10 \mathrm{deg}$ from the conical heatshield surface.

Perfect gas CFD solutions were compared to experimental results and show reasonably good agreement. CFD solutions on the Canted geometry predict more extensive flow separation and higher heating on the flap compared to data. Flight predictions for atmospheric entry from a 2005 launch were computed with the LAURA code using an 8-species Mars gas in thermo-chemical non-equilibrium. A radiative-equilibrium temperature boundary condition was specified at the wall. Laminar and Baldwin-Lomax turbulent solutions were obtained at the peak heating point on the nominal entry trajectory.

Laminar heating on the Shelf configuration is identical to the Baseline level. Also, the additional running length on the Shelf geometry does not result in increased turbulent heating above the Baseline value of $63 \mathrm{~W} / \mathrm{cm}^{2}$. Peak heating rates on the Canted geometry are higher than the Baseline levels for both laminar and turbulent flow conditions. In the laminar case, the flap is predicted to cause flow separation ahead of the tab and reattachment on the flap surface. Peak heating rates on the flap edge are as high as $49 \mathrm{~W} / \mathrm{cm}^{2}$, which is $35 \%$ higher than the laminar nose heating rate. For turbulent conditions, the boundary layer is predicted to remain attached across the Canted tab hinge line. Peak heating rate is $43 \%$ higher than the Baseline level and $84 \%$ above the Canted peak laminar heating rates.

As the MSL aeroshell design matures, both experimental and computational methods will be used to predict aeroheating environments for TPS material selection and sizing. Comparisons between data and predictions will be used to validate the computational models, and CFD solutions at flight conditions will be used to predict worst-case heating levels. The predictions will include uncertainties in CFD modeling, entry states, atmospheric properties, tunnel-to-flight extrapolation, etc. for conservatism. The resulting TPS will be a robust design that has margin beyond the worst-case aeroheating environments.

\section{ACKNOWLEDGEMENTS}

The authors would like to acknowledge valuable contributions from the following people at NASA Langley Research Center: Neil Cheatwood for his assistance with the LAURA code; Derek Liechty and Brian Hollis for providing experimental data and discussing the results.

\section{REFERENCES}

1. Lockwood, M. K., Powell, R. W., Graves, C. A., and Carman, G. L., "Entry System Design Considerations for Mars Landers," AAS 01-023, $24^{\text {th }}$ Annual AAS Guidance and Control Conference, Breckenridge, $\mathrm{CO}$, January-February 2001.

2. Lockwood, M. K., Sutton, K., Prabhu, R., and Powell, R. W., "Entry Configurations and Performance Comparisons for the Mars Smart Lander," AIAA Paper 2002-4407, AIA A Atmospheric Flight Mechanics Conference \& Exhibit, Monterey, CA, August 2002.

3. Edquist, K. T., Liechty, D. S., Hollis, B. R., Alter, S. J., and Loomis, M. P., "Aeroheating Environments for a Mars Smart Lander," AIAA Paper 2002-4505, AIAA Atmospheric Flight Mechanics Conference \& Exhibit, Monterey, CA, August 2002.

4. Liechty, D. S. and Hollis, B. R., "Heat Shield Cavity Parametric Experimental Aeroheating for a Proposed Mars Smart Lander Aeroshell," AIAA Paper 2002-2746, AIAA Fluid Dynamics Conference \& Exhibit, St. Louis, MO, June 2002.

5. Hollis, B. R. and Liechty, D. S., "Boundary Layer Transition Correlations and Aeroheating Predictions for Mars Smart Lander," AIAA Paper 2002-2745, AIAA Fluid Dynamics Conference \& Exhibit, St. Louis, MO, June 2002.

6. Liechty, D. S. and Hollis, B. R., "Control Surface and Afterbody Experimental Aeroheating for a Proposed Mars Smart Lander," AIAA Paper 20024506, AIAA Atmospheric Flight Mechanics Conference \& Exhibit, Monterey, CA, August 2002. 
7. Murphy, K. J., Horvath, T. J., Erickson, G. E., and Green, J. M., "Supersonic Aerodynamic Characteristics of Proposed Mars '07 Smart Lander Configurations," AIAA Paper 2002-4409, AIAA Atmospheric Flight Mechanics Conference \& Exhibit, Monterey, CA, August 2002.

8. Bobskill, G. J., Parikh, P. C., and Tyler, E. D., "Aerodynamic Database Development for Mars Smart Lander Vehicle Configurations," AIAA Paper 2002-4411, AIAA Atmospheric Flight Mechanics Conference \& Exhibit, Monterey, CA, August 2002.

9. Striepe, S. and Balaram, B., "Mars Smart Lander Simulations for Entry, Descent, and Landing," AIAA Paper 2002-4412, AIAA Atmospheric Flight Mechanics Conference \& Exhibit, Monterey, CA, August 2002.

10. Brauer, G. L., Cornick, D. E., and Stevenson, R., "Capabilities and Applications of the Program to Optimize Simulated Trajectories (POST)," NASA CR-2770, February 1987.

11. Fay, J. A. and Riddell, F. R., "Theory of Stagnation Point Heat Transfer in Dissociated Air," Journal of the Aeronautical Sciences, Vol. 25, No. 2, 1958.

12. Cheatwood, F. M. and Gnoffo, P. A., "User's Manual for the Langley Aerothermodynamic Upwind Algorithm (LAURA)," NASA TM-4674, April 1996.

13. Papadopoulos, P., Prahbu, D., Olynick, D., Chen, Y. K., and Cheatwood, F. M., "CFD Code Validation and Comparisons for Mars Entry Simulations," AIAA Paper 98-0272, AIAA Aerospace Sciences Meeting \& Exhibit, Reno, NV, January 1998.

14. Queen, E. M., Cheatwood, F. M., Powell, R. W., Braun, R. D., and Edquist, C. T.: "Mars Polar Lander Aerothermodynamic and Entry Dispersion Analysis," Journal of Spacecraft and Rockets, Vol. 36, No. 3, May-June, 1999.

15. Park, C., Howe, J. T., Jaffe, R. L., and Candler, G. V., "Review of Chemical-Kinetic Problems of Future NASA Missions, II: Mars Entries," Journal of Thermophysics and Heat Transfer, Vol. 8, No.1, January-March 1994.
16. Roe, P. L., "Approximate Reimann Solvers, Parameter Vectors and Difference Schemes," Journal of Computational Physics, Vol. 43, No. 2, 1981.

17. Yee, H. C., "On Symmetric and TVD Upwind Schemes," NASA TM-86842, September 1985.

18. Baldwin, B. and Lomax, H., "Thin Layer Approximation and Algebraic Model for Separated Turbulent Flows," AIAA Paper 78-0257, 1978.

19. Cheatwood, F. M., and Thompson, R. A., "The Addition of Algebraic Turbulence Modeling to Program LAURA," NASA TM-107758, April 1993.

20. Dhawan, S. and Narashima, R., "Some Properties of Boundary Layer Flow from Laminar to Turbulent Motion," Journal of Fluid Mechanics, Vol. 1, Part 4, January 1958.

21. Steinbrenner, J. P. and Chawner, J., "Gridgen's Implementation of Partial Differential Equation Based Structured Grid Generation Methods", Proceedings, 8th International Meshing Roundtable, South Lake Tahoe, CA, October 1999.

22. Sorenson, R. L. and Alter, S. J., "3DGRAPE/AL: The Ames/Langley Technology Upgrade", Surface Modeling, Grid Generation, and Related Issues in Computational Fluid Dynamic (CFD) Solutions, NASA CP-3291, May 1995.

23. Alter, S. J., "The Volume Grid Manipulator (VGM): A Grid Reusability Tool", NASA CR4772, April 1997.

24. Simeonides, G., "Hypersonic Shock Wave Boundary Layer Interactions over Simplified Deflected Control Surface Configurations", Special Course on Shock-Wave/Boundary-Layer Interactions in Supersonic and Hypersonic Flows, AGARD-R-792, August 1993.

25. Horvath, T. J., Berry, S. A., and Merski, N. R., "X38 Experimental Aerothermodynamics", AIAA Paper 2000-2685, AIAA Thermophysics Conference, Denver, CO, June 2000. 